\title{
Energy and Exergy Analysis of a Refrigeration System with Vapor Injection Using Reciprocating Piston Compressor
}

\author{
Hao-jie TANG ${ }^{\mathrm{a}}$, Shu-xi ZHENG ${ }^{\mathrm{b}}$, Yu-tao YANGc, Chao WANG ${ }^{\mathrm{d}}$, You-xin ZHAO ${ }^{\mathrm{e}}$ and Su-yan HE f,* $^{\mathrm{f}}$ \\ School of Mechanical and Electrical Engineering, Qingdao University, Qingdao 266071, China \\ a646149553@qq.com, b893471488@qq.com, c359662164@qq.com, d2859630915@qq.com, \\ e18753296188@139.com, fhesuyan67829@sina.com \\ *He SuYan
}

\begin{abstract}
Vapor injection systems have been used on scroll compressor and rotary compressor. Literature about the use of vapor injection on reciprocating piston compressor are rare. In order to increase the application range of the piston compressor, based on the single stage circulatory system, a reciprocating piston compressor with injected quasi two-stage compression system was proposed. The experiment device with vapor injection is built by modifying the reciprocating piston compressor. Analysis of exergy losses and exergy efficiency of the system are carried out. The results show that the intermediate injection system can reduce exergy loss system and expand the application range of reciprocating piston compressor.
\end{abstract}

Keywords-reciprocating piston compressor; Intermediate injection; exergy destruction; exergy analysis

\section{INTRODUCTION}

In recent years, with the continuous development of the refrigeration industry, compressor technology is also improved. Piston compressor with power less than 16HP was crowded out by the progressively expanded scroll compressor; In low temperature applications, more than $40 \mathrm{HP}$ piston compressor section was supplanted by the small screw compressor. Although the high and low temperature market was occupied by other models, the piston compressor in the range of $16 \mathrm{HP}-40 \mathrm{HP}$ still has a high performance-price ratio, faced with high challenge, piston compressors are competitive in the future market.

Compared with the two stage compression refrigeration system, the quasi two stage compression system was greatly simplified, the various compressor quasi two stage compression cycle can adapt to the changing work conditions. Heating and cooling capacity and efficiency are improved when compressors are off-design conditions. The performance of the system is stable, and easy to increase the refrigerating capacity and COP after a simple transformation of the original machine [1-3].

However, the quasi-two-stage compression cycle with vapor injection has been widely used in the screw compressors and scroll compressors systems [4-8]. Literature about piston compressor with vapor injection are rare. The paper presents a refrigeration cycle of piston compressor with vapor injection (PCVI). The single stage refrigeration compression cycle (SSRC) is regarded as the contrast. The two systems are compared and analyzed.

\section{CYCLE SYSTEM DESCRIPTION}

The schematic diagram of experiment device is showed in Fig.1, and the pressure enthalpy diagram of the system is expressed in Fig.2. The baseline single stage refrigeration cycle was 1-2-4-5-1, the main difference between the PCVI and the SSRC was that the high pressure refrigerant liquid from the condenser was divided into two ways, refrigeration loop 4'-5-1-2'-1 and injection loop 4-6-7, the 7-9-8 was refrigerant and refrigeration vapor mixing process, the 1-9-2' was a compression process. Part of refrigerant with medium temperature and high pressure from the condenser outlet was injected into the cylinder compression stroke of the reciprocating piston compressor in order to achieve the effect of quasi-two-stage compression.

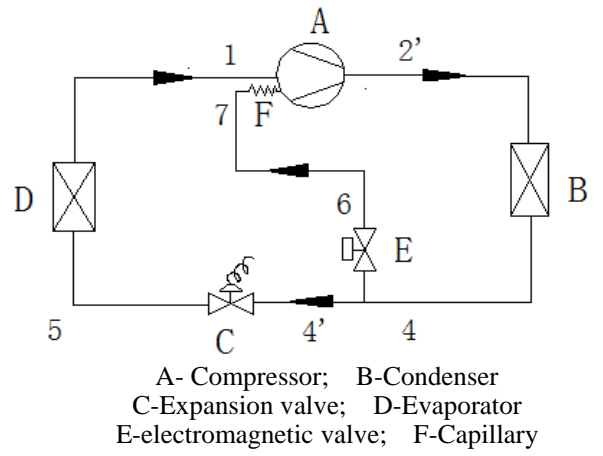

Figure 1. Schematic diagram of the experiment device

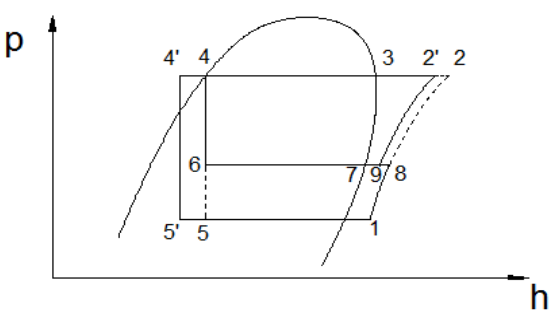

Figure 2. Pressure-enthalpy diagram of the PCVI and SSRC 


\section{THERMAL ANALYSIS OF THE SYSTEM}

The refrigeration system uses R134a as the refrigerant, tests are carried out under the condition of atmosphere pressure $0.1 \mathrm{MPa}$, relative humidity $75 \%$, power $220 \mathrm{~V} / 50 \mathrm{HZ} \pm 5 \%$. Two sets of data were recorded by measuring the normal operation of the contrast (SSRC) and the system with vapor injection (PCVI).

The following assumptions were made for the energy analysis and exergy analysis:

1) Each circulation component is in a stable state and the flow is steady;

2) The variation of potential energy and kinetic energy of refrigerant at the inlet and outlet were negligible;

3) Throttling process is the isoenthalpy process Pressure drop and heat losses of refrigerant in the cycle were neglected.

The energy analysis method based on the first law of thermodynamics is used to evaluate the performance of the total refrigeration system. The result is showed in table 1.

TABLE I. REFRIGERATION PARAMETER OF SSRC AND PCVI.

\begin{tabular}{|c|c|c|c|c|}
\hline System & $\mathrm{q}$ & $\mathrm{W}$ & $\mathrm{Q}$ & COP \\
\hline SSRC & 165.1 & 440.0 & 595.7 & 1.35 \\
\hline PCVI & 169.8 & 484.0 & 579.3 & 1.20 \\
\hline
\end{tabular}

As can be seen from Table 1, the PCVI improved the unit refrigeration capacity, but because of the refrigerant injection process without economic heat exchanger, the total refrigeration capacity was reduced. Intermediate injection of the refrigerant compressor caused a slight increase in compressor power leading to the COP of IRC declined.

In order to further evaluate the intensity of the irreversibility at every cycle component, the exergy analysis is employed in the study to further explore the thermodynamic performance of the two systems [9-11].

\section{A. For Compressor Process}

The SSRC

$$
E x_{\text {d.com }}=T_{0}\left(\mathrm{~s}_{2}-\mathrm{s}_{1}\right)
$$

The PCVI

$$
E x_{\text {d.com }}=T_{0}\left(s_{2^{\prime}}-s_{1}\right)
$$

$$
E x_{\text {d.con }}=h_{2}-T_{0} s_{2}-\left(h_{4}-T_{0} s_{4}\right)
$$

The PCVI

$$
E x_{\text {d.con }}=h_{2^{\prime}}-T_{0} s_{2^{\prime}}-\left(h_{4^{\prime}}-T_{0} s_{4^{\prime}}\right)
$$

\section{For Expansion Process}

The SSRC

$$
E x_{d . \exp }=T_{0}\left(s_{5}-s_{4}\right)
$$

The PCVI

$$
E x_{d . \exp }=T_{0}\left(s_{5^{\prime}}-s_{4^{\prime}}\right)
$$

\section{For Evaporation Process:}

The SSRC

$$
E x_{\text {d.eva }}=T_{0}\left(s_{1}-s_{5}\right)-\left(h_{1}-h_{5}\right) \frac{T_{0}}{T_{0}^{*}}
$$

The PCVI

$$
E x_{\text {d.eva }}=T_{0}\left(s_{1}-s_{5^{\prime}}\right)-\left(h_{1}-h_{5^{\prime}}\right) \frac{T_{0}}{T_{0}^{*}}
$$

Total exergy destruction:

$$
E x_{d . t}=E x_{\text {d.com }}+E x_{\text {d.con }}+E x_{\text {d.exp }}+E x_{\text {d.eva }}
$$

Exergy efficiency:

$$
\eta_{E x}=1-\frac{E x_{d . t}}{W_{c o m}}
$$

The results of exergy analysis of the two systems were shown in exergy flow diagram Fig. 3, when the condensing pressure was $0.58 \mathrm{MPa}$.

Fig.3 shows that the compression destruction of SSRC system accounted for $20.3 \%$ of the compressor exergy input. In order to minimize the energy consumption, energy saving should be the compression process. The compressor destruction and the evaporator destruction of the system PCVI are reduced, while condenser destruction and expansion destruction of the system PCVI are raised. Since the the throttling process of PCVI system did not use methods such as an economic heat exchanger or an ejector, the heat recovery and other methods to reduce the throttle loss [12]. The exergy destruction of expansion process is raised in the PCVI system, thus leading to the exergy efficiency reduction of the system.

\section{B. For Condenser Process}

The SSRC 


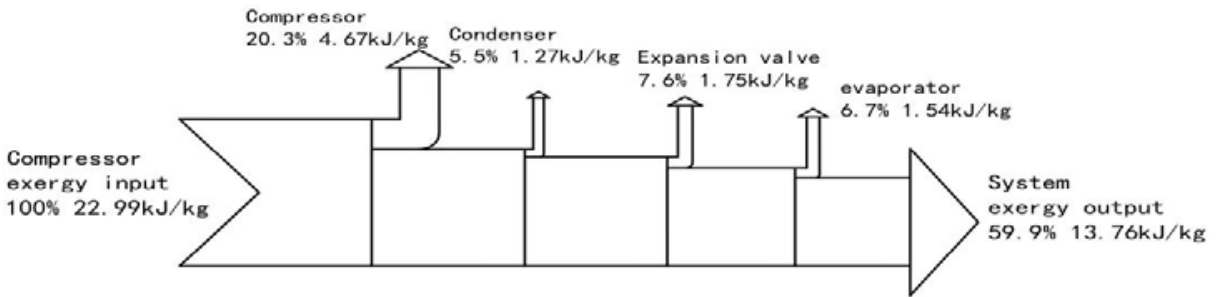

(a)

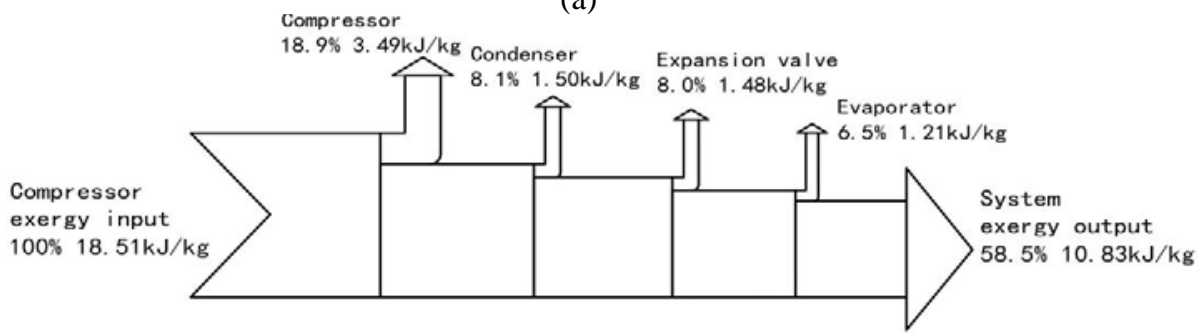

(b)

Figure 3. Exergy flow diagrams for the SSRC (a) and PCVI (b)

\section{CONCLUSION}

The PCVI system reduced total system exergy destruction, especially the compression exergy destruction. The PCVI system expanded the use range of the piston compressor, and improved the performance of compressor in low temperature and high temperature conditions. The system has only one compressor, which makes the system institutions simple, easy to maintenance. The system should be more widely used. Because no measures are taken to reduce the throttling losses in the present study, further improvement of the PCVI system will be carried out in the next work.

\section{REFERENCES}

[1] Q.H. Chai, G.Y. Ma, Y. Jiang, "Thermodynamic Analysis Scroll Compressor Refrigeration Cycle with the Economy,” Journal of Bao Tsinghua University (Natural Science), vol. 43 (10), 2003, pp. 1401-1404

[2] S.X. Xu, G.Y.Ma, Q. Liu, Z.L. Liu, "Experiment Study of an Enhanced Vapor Injection Refrigeration/Heat Pump System Using R32,” International Journal of Thermal Sciences, Vol. 68, 2013, pp.103-109.

[3] J. Shen, G.J. Han, Z.H. Sun, “The Comparison of Quasi-tertiary Vapor-compression Refrigeration System and Double-stage Compression Refrigeration System,” Cryogenics \& Superconductivity, vol. 38(2), 2010, pp. 48-50.
[4] S.X. Xu, G.Y. Ma, L. Peng, "Performance Study on Quasi Two-stage Compression Cycle Composed by Different Type of Refrigerant Compressor,” Petro-Chemical Equipment, vol. 38(4), 2009, pp. 1-4.

[5] Y.Z. Liu,Y.F. Zhao, X. Feng, "Exergy Analysis for a Freeze-drying Process,” Applied Thermal Engineering vol. 28, 2008, pp. 675-690.

[6] D. Zhang, J.P. Li, W. Liu, "Evaluation and Prediction of the Performance of Air-source Heat Pump," Journal of Chemical Engineering, Vol. 12, 2014, pp. 5004-5009.

[7] C.W. Roh, M.S. Kim, "Effects of Intermediate Pressure on the Heating Performance of a Heat Pump System Using R410A Vapor-injection Technique,” International Journal of Refrigeration, Vol. 34, 2011, pp. 1911-1921

[8] X. Xu, Y. Hwang, R. Radermacher, "Refrigerant Injection for Heat Pumping/Air Conditioning Systems: Literature Review and Challenges Discussions,” International Journal of Refrigeration, Vol.34, 2011, pp. 402-415.

[9] H.T. Qiao, V. Aute, R. Radermacher, "Transient Modeling of a Flash Tank Vapor Injection Heat Pump System ---Part I: Model Development," International Journal of Refrigeration, Vol. 49, 2015, pp. 169-182.

[10] G. Yan, J. Chen, J. Yu, "Energy and Exergy Analysis of a New Ejector Enhanced Auto-cascade Refrigeration Cycle,” Energy Conversion \& Management, vol.105, 2015, 509-517.

[11] Y. H. Lai, Q.W. Wang, M.X. Lv, "Exergy Analysis of the $\mathrm{R} 404 \mathrm{~A} / \mathrm{CO}_{2}$ Cascade Refrigeration System,” Journal of Shandong University, Vol. 41(6), 2011, pp. 115-121.

[12] J.H. Liu, Refrigeration throttle and reduced throttle loss with ejector mechanism[D]. Shanghai Jiaotong University, 2008. 


\section{Nomenclature}

$\begin{array}{cl}\mathrm{q} & \text { unit refrigeration capacity }(\mathrm{kJ} / \mathrm{kg}) \\ \mathrm{W} & \text { compressor power }(\mathrm{W}) \\ \mathrm{Q} & \text { refrigeration capacity }(\mathrm{W}) \\ \mathrm{COP} & \text { coefficient of performance } \\ E_{x} & \text { exergy rate of fluid }(\mathrm{kJ} / \mathrm{kg}) \\ E_{x d} & \text { exergy destruction }(\mathrm{kJ} / \mathrm{kg}) \\ \eta_{E x} & \text { exergy destruction percentage } \\ \mathrm{T}_{0} & \text { environment temperature } \\ T_{0}^{*} & \text { refrigeration temperation }\end{array}$

SSRC single stage refrigeration compression cycle

PCVI injection

\begin{tabular}{|c|c|}
\hline $\mathrm{P}$ & presssure $(\mathrm{Pa})$ \\
\hline $\mathrm{h}$ & enthalpy (kJ/kg) \\
\hline $\mathrm{S}$ & entropy $(\mathrm{kJ} / \mathrm{kg} \cdot \mathrm{K})$ \\
\hline $\mathrm{T}$ & temperature (K) \\
\hline & Subscripts \\
\hline com & compressor \\
\hline con & condenser \\
\hline exp & expansion \\
\hline eva & evaporator \\
\hline $1-9$ & state points of refrigerant \\
\hline $\mathrm{d}$ & destruction \\
\hline
\end{tabular}

